\title{
Ensuring the rational temperature conditions for concrete hardening
}

\author{
German Dzhusoev ${ }^{1}$, Michael Orlov ${ }^{1}$, Olga Vasileva ${ }^{1, *}$ and Alexey Slavin ${ }^{1}$ \\ ${ }^{1}$ Moscow State University of Civil Engineering, 26, Yaroslavskoe Shosse, Moscow, Russia
}

\begin{abstract}
One of the important aspects of the production technology of monolithic reinforced concrete is to ensure the rational temperature hardening of concrete that can provide high-quality concrete with a minimum duration of heat treatment and minimize energy costs. The article contains ways to solve the problem of ensuring a rational temperature setting of hardening. The task requires the development of a general method for calculating the temperature field of concrete in a hardening reinforced concrete structure. The proposed method of calculating considers a mathematical model of the temperature field in a hardening concrete structure of any shape with different conditions on the heat exchange surfaces and can be applied in various ways of heat treatment of concrete. For solving the equations of thermal conductivity and kinetics of heat release of concrete, the initial and boundary conditions must be specified. Moreover, the influence of reinforcing and simulation of heat distribution in the frozen basis is studied.
\end{abstract}

\section{Introduction}

Currently, in the construction industry, the direction of forming a set of measures for the use of technology and the organization of construction by the method of concrete and reinforced concrete monolithic housing construction has received a significant accelerated volume of implementation. [1-3]. An important element in the production of reinforced concrete technology is to ensure the rational temperature concrete hardening [4-7]. For a satisfactory solution to this problem, it is necessary to have a common method of calculating the temperature field in the hardening concrete structure [8-13,17].

The implementation of this method of calculation using computer modeling has now become possible and relevant due to the widespread use of computer technology in various fields of the economy. [5, 18]. Under the influence of the inhomogeneous and nonstationary temperature field in the hardening concrete thermal stress arises in it as a condition that can lead to a decrease in the final strength of the structure $[1,3]$. Therefore, it is necessary to know the dynamics of temperature fields in concrete structures for different methods of heat treatment. By choosing the most efficient mode of heat treatment of concrete structures, it is possible to provide high-quality concrete with a minimum duration of heat treatment and minimize energy costs $[8,9]$. During the heat treatment of the concrete, the temperature field in the structure can be controlled by changing the initial

\footnotetext{
*Corresponding author: olgaolka086@gmail.com
} 
concrete temperature, the heating power of the heating elements and heat exchange conditions on the surface of the structure [21-24]. There is the task of finding such heat treatment mode, in which the temperature field has the desired characteristics. These characteristics include temperature, its rate of rising and temperature gradient [16,20].

The first step in solving the problem of heat treatment mode is to create a sufficiently accurate mathematical model of the temperature field in the hardening concrete.

The second step should be devoted to the numerical solution of the equations of the model that allows us to calculate the temperature field in the hardening concrete structure using computer software. With this method, you can use the computer software to investigate the dynamics of the temperature field at various modes of heat treatment and to develop the most rational modes without resorting to a big series of scientific experiments.

\section{Methods}

The article presents a mathematical model of the temperature field in a hardening concrete structure of any shape with different conditions on the heat exchange surfaces. A locally one-dimensional scheme is applied for the numerical solution of the model equations. The proposed method of calculating the temperature field can be used in various ways of heat treatment of concrete, when choosing the power and thermal insulation of the designed heating formwork, as well as for the calculation of the thermal conditions of buildings and structures.

A mathematical model of the temperature field. The heat equation. The propagation of heat in the concrete in the absence of intensive sources (waste) water and steam is mainly determined by the heat conductivity. The heat equation for a three-dimensional domain $G$ has the form:

$$
\begin{aligned}
& C \frac{\partial U}{\partial t}=L u+f, \quad L u=\sum_{P=1}^{3} L_{p} u, \\
& L u=\frac{\partial y}{\partial x_{p}}\left(\lambda p \frac{\partial u}{\partial x_{p}}\right), \vec{x}=\left(x_{1}, x_{2}, x_{3}\right) \in G
\end{aligned}
$$

where $\mathrm{C}$ - specific volumetric heat capacity, $\mathrm{J} / \mathrm{m}^{3 \circ} \mathrm{C} ; \lambda \rho$ - coefficient of thermal conductivity, $\mathrm{W} / \mathrm{m}^{\circ} \mathrm{C} ; \mathrm{hr}(\mathrm{P}=1 ; 2 ; 3)$ the Cartesian rectangular coordinates, $\mathrm{m} ; \mathrm{t}$ - time, sec.; $\mathrm{u}$ - temperature, ${ }^{\circ} \mathrm{C}$; $\mathrm{f}$ - intense inner heat, $\mathrm{W} / \mathrm{m}^{3}$.

A task of the area. Area $\mathrm{G}$ must include not only the fresh concrete, temperature field that we are interested in (the temperature of which is studied), but also the parts of the solids that are in contact with it (for example, the previously poured concrete, soil foundation, etc.).

\section{Results}

Influence of reinforcement. Steel reinforcement in concrete usually takes a small relative volume so its effect on the values of $\mathrm{C}$ and $\mathrm{j}$ insignificant. However, since the coefficient of thermal conductivity $(\lambda \rho)$ of steel is much larger than $\lambda \rho$ of concrete, it is necessary to consider the heat flows that extend on rebars. Thus, the thermal conductivity $(\lambda \rho)$ also depends on the location and direction of the reinforcement (anisotropic medium).

Internal heat sources. The intensity of internal heat sources is the sum of the intensity of the energy flow from the outside (electric heating, etc.) and the intensity of the heat produced by the concrete itself. The first term is the control action and is given as a function of position and time. Concrete heat intensity depends on the temperature and conditions of the concrete. It should be noted that the hardening concrete thermal 
conductivity also depends on temperature and its state. Currently, this issue needs to be a pilot study.

Simulation of heat distribution in the frozen basis. Let us look at pouring concrete on a partially frozen subgrade. During the process of hardening of concrete, the interface between the thawed and frozen zones in the ground moves. The temperature at the boundary between zones is constant and equal to the phase transition temperature. Each zone temperature satisfies the equation (1); moreover, the heat capacity and thermal conductivity in the frozen and thawed zones are different. Each point $\mathrm{g}=(\mathrm{g}, \mathrm{gg}, 5 \mathrm{z}) \mathrm{E}$ moves along the normal to the interface at that point. The values related to the frozen zone will be denoted by the index 1 , and in the melt zone - index 2 . Suppose 2 is the unit vector normal to the interface from the melt zone to the frozen. Then the velocity of the interface is determined by the heat balance equation.

$$
\mathrm{q}_{\mathrm{f}}\left(\frac{\mathrm{d} \vec{\xi}}{\mathrm{dt}} * \overrightarrow{\mathrm{n}}\right)=\lambda_{1} \frac{\partial \mathrm{u}}{\partial \overrightarrow{\mathrm{n}}}\left|-\lambda_{2} \frac{\partial \mathrm{u}}{\partial \overrightarrow{\mathrm{n}}}\right|
$$

Where $\mathrm{q}$ is the specific heat of the volume phase transition, $\mathrm{J} / \mathrm{m}^{3}$.

Instead of the two heat conduction equations for the frozen and thawed areas and bonding heat balance equation, you can use one type of equation (1), in which the heat of the phase transition takes into account changes by an artificial change in the heat capacity of the environment.

In the real ground interface between frozen and thawed areas is not surface. To account for the latent heat is introduced $b$ - shaped continuous function $b\left(u-U_{\text {кр }}, \Delta\right)$ which is different from zero only in the interval $\left(\mathrm{u}-\Delta, \mathrm{U}_{\text {кр }}\right)$ and satisfies the normalization condition.

$$
\int_{\mathrm{u}_{\mathrm{kr}}-\Delta}^{\mathrm{u}_{\mathrm{kr}}} \mathrm{b}\left(\mathrm{u}-\Delta, \mathrm{u}_{\mathrm{kr}}\right) \mathrm{du}=1-\frac{1}{\mathrm{q}_{\mathrm{f}}} \int_{\mathrm{u}_{\mathrm{kr}}-\Delta}^{\mathrm{u}_{\mathrm{kr}}} \overrightarrow{\mathrm{c}}(\mathrm{u}) \mathrm{du}
$$

Then the process of heat distribution in the frozen and thawed areas is modeled by one equation with thermal capacity (5) and thermal conductivity $\lambda=\vec{\lambda}(\mathrm{u})$.

$$
\mathrm{c}=\overrightarrow{\mathrm{c}}(\mathrm{u})+\mathrm{q}_{\mathrm{f}} \delta\left(\mathrm{u}-\Delta, \mathrm{u}_{\mathrm{kr}}\right) ;
$$

\section{Discussion}

The equation of kinetics of heat release of concrete. The intensity of hardening concrete heat at any given time is determined by the temperature and condition of the concrete that established to this point in time.

Concrete condition parameter. Fundamentally, it is possible to determine the state of hardening concrete with a set of physical parameters that change during the hardening process $[14,15]$. If the concrete does not have destructive changes its state is determined by the composition of the concrete mix and some parameter that monotonously changes during the process of hardening of the concrete $[11,12]$. Thus, we can assume that the physical parameters are uniquely expressed through their initial values and this generalized parameter. As such a parameter, it is convenient to take the specific heat release of concrete $\mathrm{Q}\left(\mathrm{J} / \mathrm{m}^{3}\right)$ or the relative heat where $\mathrm{Q}_{\text {mah }}$ - maximum specific heat of concrete, $\mathrm{J} / \mathrm{m}^{3}$.

General form of the equation of kinetics of heat release of concrete. As it is described above, concrete heat intensity is function of the temperature and the relative heat:

$$
\frac{\mathrm{dQ}}{\mathrm{dt}}=\mathrm{Q}_{\max } \mathrm{E}(\mathrm{u}, \omega)
$$




$$
\frac{\mathrm{d} \omega}{\mathrm{dt}}=\mathrm{E}(\mathrm{u}, \omega)
$$

Where $\mathrm{E}(\mathrm{U}, \mathrm{W})$ - heat release function coefficients determined by the composition of the concrete mix. This equation is the equation of the state of concrete and, at the same time, the equation of the kinetics of heat release, since the relative heat release of concrete is chosen as the state parameter (Q). Heat function can be represented as the product of a function of temperature $\varphi$ and state function $\psi$.

$$
\mathrm{E}(\mathrm{u}, \omega)=\varphi(\mathrm{u}) \psi(\omega)
$$

For isothermal modes of hardening, such a representation is equivalent to the regularity of temporarily equal heat releases, which is in good agreement with experimental data in $\mathrm{w}_{\mathrm{\kappa p}}<\mathrm{w}>1$ region, where $\mathrm{w}_{\text {кр }}$ - the critical value of the relative heat in which the heat release rate in the isothermal mode reaches a maximum.

In the region $0<\mathrm{w}<\mathrm{W}_{\mathrm{\kappa p}}$ the regularity of times equal heat generation is violated, therefore in this area function cannot be represented as a product. However, the difference between $\mathrm{w}_{\mathrm{\kappa p}}$ and $\mathrm{w}_{0}$ (relative heat release of concrete laid in the formwork) is small, so for practical calculations, it is permissible to have a heat release function in the equation of heat release kinetics as a product in the field $\omega_{0} \prec \omega \prec 1$.

Heat function of the concrete. The state function is defined as:

$$
\psi(\omega)=(1-\omega)^{v}
$$

Where $\mathrm{v}$ - a constant coefficient.

The best approximation of the experimental data to the heat dissipation of the concrete is provided by two functions:

$$
\begin{gathered}
\widetilde{\varphi}(\mathrm{u})=\mathrm{K} \exp \left(\frac{\mathrm{u}-20}{\xi}\right), \\
\bar{\varphi}(\mathrm{u})=\mathrm{K}\left(\frac{\mathrm{u}-\mathrm{u}_{3}}{20-\mathrm{u}_{3}}\right)^{\zeta},
\end{gathered}
$$

Where $\mathrm{u}_{3}$ - freezing point of the concrete, ${ }^{\circ} \mathrm{C} ; \mathrm{K}, \xi, \zeta$ - coefficients depending on the composition of the concrete mix.

Function (a) leads to the known relationship:

$$
\frac{\widetilde{\varphi}\left(\mathrm{u}_{2}\right)}{\widetilde{\varphi}\left(\mathrm{u}_{1}\right)}=2^{\frac{\mathrm{u}_{2}-\mathrm{u}_{1}}{\varepsilon}}, \mathcal{E}=\xi * \ln 2
$$

Thus, the concrete heat function takes the form:

$$
\mathrm{E}(\mathrm{u}, \omega)=\bar{\varphi}(\mathrm{u}) \psi(\omega)=\mathrm{K}\left(\frac{\mathrm{u}-\mathrm{u}_{3}}{20-\mathrm{u}_{3}}\right)^{\zeta}(1-\omega)^{v},
$$

Where the function $\bar{\varphi}(\mathrm{u})$ can be replaced by $\widetilde{\varphi}(\mathrm{u})$. Moreover, the coefficients of heat function is determined experimentally.

The heat equations and kinetics of heat release of concrete should be supplemented by initial and boundary conditions.

Initial conditions. The initial condition for the heat equation is the temperature distribution in region 0 at the initial moment of the heat treatment process of the concrete mix

$$
\mathrm{U} / \mathrm{t}=0=\mathrm{u}_{0}(\mathrm{x})
$$


The area occupied by the concrete mix, the function $\mathrm{u}_{0}(\mathrm{x})$ can be assumed constant. In areas previously occupied by the poured concrete or gravel base should be made a real temperature distribution. If this distribution is not known, it must first be calculated by the method described in the article. The initial condition for the kinetics of heat dissipation of concrete is the distribution of the state parameter in the region $\mathrm{O}$ at the initial moment of the heat treatment process:

$$
\omega / \mathrm{t}=0=\omega_{0}(\mathrm{x})
$$

The area occupied by the concrete mix, the function $\omega_{0}(x)$ assumed to be constant. If the area has a zone of previously poured concrete, the process of heat generation in which has not been completed yet, then the distribution of the state parameter in this zone should be obtained by preliminary calculation. In the rest of the region, the state parameter is equal to one. Boundary conditions. The condition of constant temperature is set on the part of the boundary $\mathrm{G}$ of the region $\mathrm{G}$, passing in the ground or in the old concrete. In this case, you should move the border area. The boundary condition for the rest of the boundaries is the heat balance equation:

$$
\left[\lambda \frac{\partial u}{\partial \vec{n}}+\frac{1}{R}(u-v)+c_{n} \frac{\partial u}{\partial t}\right]_{\vec{x} \in r}=q_{n}
$$

Where: $\mathrm{R}$ - thermal resistivity, $\left(\mathrm{m}^{20} \mathrm{C}\right) / \mathrm{W}$;

$\frac{1}{\mathrm{R}}-$ coefficient of heat transfer, $\mathrm{W} /\left(\mathrm{m}^{2 \circ} \mathrm{C}\right)$;

$\mathrm{V}$ - environment temperature, ${ }^{\circ} \mathrm{C}$;

$\mathrm{c}_{\mathrm{n}}-$ heat capacity of formwork, $\mathrm{J} /\left(\mathrm{m}^{2 \circ} \mathrm{C}\right)$;

$\mathrm{q}_{\mathrm{n}}$ - specific power of heating formwork, $\mathrm{W} / \mathrm{m}^{2}$.

The values $\mathrm{R}, \mathrm{c}_{\mathrm{n}}$ and $\mathrm{q}_{\mathrm{n}}$ may depend on coordinates and time.

For flat boundary thermal resistance is the expression:

$$
\mathrm{R}=\frac{\mathrm{d}}{\lambda}+\frac{1}{\alpha}
$$

Where $\alpha$ - outside film coefficient of heat transfer that depends on wind speed, temperature, emissivity and orientation of the border area, $\mathrm{W} /\left(\mathrm{m}^{2 \circ} \mathrm{C}\right)$;

$\mathrm{d}$ - thickness of thermal insulation layer, $\mathrm{m}$;

$\lambda$ - coefficient of thermal conductivity of heat insulating material, $\mathrm{W} /\left(\mathrm{m}^{2 \circ} \mathrm{C}\right)$.

The heat transfer resistance may be significantly less in some areas where there is a metallic connection of the deck with the outer surface of the formwork. In this case, the corresponding value $\alpha$ is introduced into the boundary condition. In the presence of a steel deck, it is necessary to consider the flow of heat that spreads over the deck.

\section{Conclusions}

The article considered the task of ensuring rational temperature conditions for concrete hardening. To solve this problem, we examined the parameters necessary for calculating the thermal regime of concrete and some of the components that affect the temperature field of concrete. There are some conclusions:

- The method of calculating the temperature field explored in the article can be applied to various methods of heat treatment.

- Thermal conductivity in general determines the process of heat distribution in concrete. The article presented the heat equation for the three-dimensional region.

- It is necessary to take into account not only the area of freshly poured concrete, but also the areas of solids that are in contact with it. 
- The reinforcement has almost no effect on the temperature conditions of the concrete.

- Requires an additional experimental study of the dependence of the thermal conductivity of hardening concrete on its temperature and condition.

- The state of hardening concrete may be determined by some set of physical parameters that vary during the hardening process.

- The heat intensity of concrete is a function of temperature and relative heat.

- To solve the heat conduction equation and the kinetics of heat generation in concrete, it is necessary to set the boundary conditions.

In addition, the specific power of the heating formwork is the main insulating effect on the temperature field of concrete. It can be changed during the hardening process according to any technologically acceptable law in order to choose the most rational mode of heat treatment.

\section{References}

1. A.O. Adamtsevich, Stroitel'nye Materialy 1, 53-57 (2015)

2. A.O. Adamtsevich, A.P. Pustovgar, A.V. Eremin, S.A. Pashkevich, Stroitel'nye Materialy 7, 59-61 (2013)

3. A.V. Alabin, The modern high technologies 7, 7-11 (2017)

4. I.A. Engovatov, B.K. Bylkin, A.N. Kozhevnikov, Theses of reports of the ninth international scientific and technical conference, 305-309 (2014)

5. A.V. Ishin, Technology and the organization of construction production 2, 10-16 (2014)

6. M.F. Kuzhin, Science review 17, 337-340 (2015)

7. P.P. Oleynik, V.I. Brodsky, Industrial and Civil Engineering 3, 100-103 (2017)

8. P.P. Oleynik, T.K. Kuzmina, News of higher educational institutions. technology of textile industry 3, 11-16 (2017)

9. P. Oleynik, S. Sinenko, B. Zhadanovsky, V. Brodsky, M. Kuzhin, MATEC Web of Conferences 86 (2016) doi:10.1051/matecconf/20168604059

10. S.A. Pashkevich, Nauchno-tehnicheskij vestnik Povolzh'ja, Scientific and technical proceedings of the Volga region 3, 191-194 (2014)

11. A.P. Pustovgar, The journal of Volgograd State University of Architecture and Civil Engineering 2(33), 10 (2014)

12. A.P. Pustovgar, P.A. Lavdansky, A.V. Zhuravlev, A.V. Esenov, V.V. Medvedev, A.D. Nauchno-tehnicheskij vestnik Povolzh'ja, Scientific and technical proceedings of the Volga region 5, 285-287 (2014)

13. M.V. Shitov, Collection of works XX of the International interuniversity scientific and practical conference of students, undergraduates, graduate students and young scientists, 1197-1200 (2017)

14. A. Sigalov, S. Sinenko, T. Poznahirko, MATEC Web of Conferences 117 (2017) doi:10.1051/matecconf/201711700158

15. S.A. Sinenko, B.V. Zhadanovsky, A.Yu. Slavina, BST - Bulletin of Construction Equipment 4, 43-45 (2018)

16. S. Sinenko, A. Slavina, Paper presented at the MATEC Web of Conferences 106 (2017) doi:10.1051/matecconf/201710608016 
17. H. Su, H. Jing, Q. Yin, L. Yu, Advances in Civil Engineering (2018) doi:10.1155/2018/1326503

18. V.I. Telichenko, V.S. Prokopenko, R.R. Sharapov, I.P. Boychuk, Construction mechanization 77(11), 5-8 (2016)

19. M.V. Volovik, Technology and organization of construction production 1(2), 14-18 (2013)

20. Z. Wang, A. He, G. Shi, G. Mei, International Journal of Geomechanics 18(3) (2018)

21. B.V. Zhadanovsky, A.V. Beschastyi, Mechanical processing of diamond tools by nonmetallic materials and reinforced concrete in construction (Moscow, 2017)

22. B. Zhadanovsky, S. Sinenko, Int. Journal of Applied Engineering Research 11(3), 1724-1727 (2016)

23. A.V. Denisov, A. Sprince, Magazine of Civil Engineering 80, 151-170 (2018) doi:10.18720/MCE.80.14

24. A.Y. Struchkova, Y.G. Barabanshchikov, K.S. Semenov, A.A. Shaibakova, Magazine of Civil Engineering 78, 128-135 (2018) doi:10.18720/MCE.78.10 